\title{
COMPRESSOR ENERGY AND EXERGY ANALYSIS
}

\author{
Tarek Abozaid Abobakr Abdelghany ${ }^{\mathrm{a}}$, Rafea Mohamed Abd El-Maksoud ${ }^{\mathrm{b}}$, \\ Mohamed A. A. Nawar
}

a Siemans mechanical engineer

Email address: tarekabozaid1990@gmail.com

Tel: 01098596603

b Assoc. Prof., Mechanical Power Engineering Department, Faculty of Engineering, Mattaria, Helwan University, Egypt.

Email address: brainandspirit@yahoo.com

Tel: 002-01001213728

${ }^{c}$ Assist. Prof., Mechanical Power Engineering Department, Faculty of Engineering, Mattaria, Helwan University, Egypt.

Email address: mhr291@hotmail.com

Tel: 002-01000069193

\begin{abstract}
The present work is devoted to investigate compressor performance (positive displacement or dynamic compressor) from two different points of view that are; energy and exergy. The studied compressor parameters are; compressor polytropic efficiency, compressor pressure ratio, inlet temperature, and inlet humidity. The effect of these parameters on compressor specific work consumption, compressor operating range, energy destruction, energy destruction ratio, and the first and second law efficiencies are demonstrated. The results show how the compressor behaves under different conditions. Also, the results illustrate that first and second law efficiencies provide quantitative and qualitative compressor performance assessments. The result charts help in selecting different types of compressors that having higher second law efficiency or having less exergy destruction ratio. The present paper may give an insight to understand deeply compressor performance and how to evaluate or choose the compressor with less exergy losses ratio.
\end{abstract}

Key Words: Compressor, energy, exergy, efficiency, energy destruction, pressure ratio, relative humidity. 


\section{Nomenclature}

$\begin{array}{ll}\text { AMF } & \text { Air mass function (--) } \\ \mathrm{C}_{\mathrm{p}} & \text { Specific heat at constant pressure }(\mathrm{kJ} /(\mathrm{kg} \mathrm{K}) \\ \mathrm{I}_{\text {des }} & \text { Exergy destruction }(\mathrm{kJ} / \mathrm{kg}) \\ \mathrm{I}_{\text {des ratio }} & \text { Exergy destruction ratio }(--) \\ \mathrm{K} & \text { Isentropic exponent }(--) \\ \mathrm{MMW} & \text { Mixture molecular weight }(\mathrm{kg} / \mathrm{mol}) \\ \mathrm{P} & \text { Pressure }(\mathrm{kPa}) \\ \mathrm{R} & \text { Universal gas constant }(\mathrm{kJ} / \mathrm{mol} \mathrm{K}) \\ \mathrm{RH} & \text { Relative humidity }(--) \\ \mathrm{s} & \text { Specific entropy of the humid air }(\mathrm{kJ} / \mathrm{kgK}) \\ \mathrm{T} & \text { Temperature }(\mathrm{K}) \\ \mathrm{VMF} & \text { Vapor mass function }(--) \\ \mathrm{W} & \text { Compressor specific work }(\mathrm{kJ} / \mathrm{kg}) \\ \text { Greek Symbols } \\ \eta_{\mathrm{I}} & \text { First law efficiency (--) } \\ \eta_{\mathrm{II}} & \text { Second law efficiency (--) } \\ \eta_{\mathrm{p}} & \text { Polytropic efficiency }(--) \\ \pi & \text { Compressor pressure ratio (--) } \\ \omega & \text { Specific humidity (--) } \\ \text { Subscript } & \\ 1 & \text { Inlet compressor condition } \\ 2 & \text { Outlet compressor condition } \\ \text { a } & \text { Air } \\ \text { av } & \text { Average } \\ \mathrm{m} & \text { Mixture of humid air } \\ \text { rev } & \text { Reversible } \\ \mathrm{s} & \text { Isentropic condition } \\ \text { sat } & \text { Saturation condition } \\ \mathrm{v} & \text { Vapor } \\ & \end{array}$

\section{1-INTRODUCTION}

Compressors are backbone machines in the processes of petroleum, refrigeration, chemical industries, and so on. Consequently, improvement of the compressor performance is necessary. Due to their vast applications, different investigations have been performed. Mousavi et al. (2014) demonstrated an overview of techniques to model energy consumption as well as various approaches used to control the compression air system. A state-base modelling technique is used to develop a simulation model that includes both fixed and variable speed drive compressors. Mascarenhas et al. (2019) introduced an investigation on the industrial air compressors basing on energy, exergy, 
sustainability, and emission analysis. Oldrich (2018) depicted the calculation of isentropic efficiency of centrifugal compressor working with real gas. Yang et al. (2019) investigated compressors as they are parts of compression system.

$\mathrm{Xu}$ and Amano (2010) introduced a certain design of a single-stage centrifugal compressor by using a viscous optimization method. Niazmand et. al. (2017) demonstrated the important design factors on entropy generation of a reciprocating compressor. Mohtaram et. al. (2017) investigated the effect of compressor pressure ratio on the thermodynamic performances of ammonia-water combined cycle through energy and exergy destruction, enthalpy, temperature, and flow velocity. Shukla and Singh (2014) illustrated the effect of compressor inlet temperature and relative humidity on gas turbine cycle performance.

Bader and Kissock (2000) performed an analysis of industrial air compression system. They discussed the use of exergy analysis for improving industrial energy utilization. Szablowski et al. (2017) illustrated an energy and exergy analysis of an adiabatic compressed air energy storage system showing the biggest exergy destruction condition. Ogbonnaya et al. (2019) presented a review for the energy and exergy performance of the vapor compression refrigeration system using nano-lubricant. They illustrated some critical factors that affects the performance optimization and exergy destruction within the system. Betelmal et al. (2018) introduced a study the simple gas turbine and the maximum amount of water that can be injected into the compressor. The analytical formula of exergy destruction and results showed that exergy destruction increases with water injection.

Mohamed et. al. (2011) illustrated compressors instabilities and how to suppress them by using two bleed values. Abd El-Maksoud et. al. (2013) presented a methodology to predict and modify the centrifugal compressor map. Bayomi and Abd El-Maksoud (2012) introduced a turbocharger system with two modes where intensive interest was made on the centrifugal compressor. Shukla and Singh (2014) depicted the effect of the compressor inlet conditions (inlet temperature and relative humidity) on the performance gas turbine cycle.

Compressor of different types, various parameters, and numerous applications imply a significant need to achieve many researches in different compressor fields. Furthermore, the compressor behavior according to different parameters is not fully understood especially from exergy viewpoint. Consequently, the present work aims at investigating the compressor performance (positive displacement or dynamic compressor). Energy and exergy analysis are used to understand deeply the compressor performance. Such performance is demonstrated by compressor specific work consumption, exergy destruction, exergy destruction ratio, first law efficiency, and second law efficiency. The studied parameters are; compressor polytropic efficiency, compressor pressure ratio, 
inlet temperature, and inlet humidity. The present work gives different viewpoints of how the compressor behaves at different operating conditions.

\section{FIRST AND SECOND LAW EFFICIENCIES}

To reveal how to achieve the aim of the present study, Fig. 1 demonstrates T-s diagram of a typical compressor (positive or dynamic compressor) with certain polytropic efficiency, $\eta_{\mathrm{p}}$, and pressure ratio, $\pi$. Humid air enters the compressor at state 1 with inlet ambient temperature $\mathrm{T}_{1}$ and relative humidity $\mathrm{RH}$ and discharges at the state 2 with outlet temperature $\mathrm{T}_{2}$. On the other hand, the state $2 \mathrm{~s}$ represents isentropic outlet condition of the humid air. Therefore, compressor isentropic work and its actual work can be determined. Also, first law efficiency, $\eta_{\mathrm{I}}$, is specified by dividing the isentropic work over the actual work. On the other side, the compressor second law efficiency, $\eta_{\mathrm{II}}$, can be presented by the reversed work over the actual work. The reversed work is determined by the actual work minus the exergy destruction. From this Figure, two different insights can be presented that are; energy insight and exergy insight.

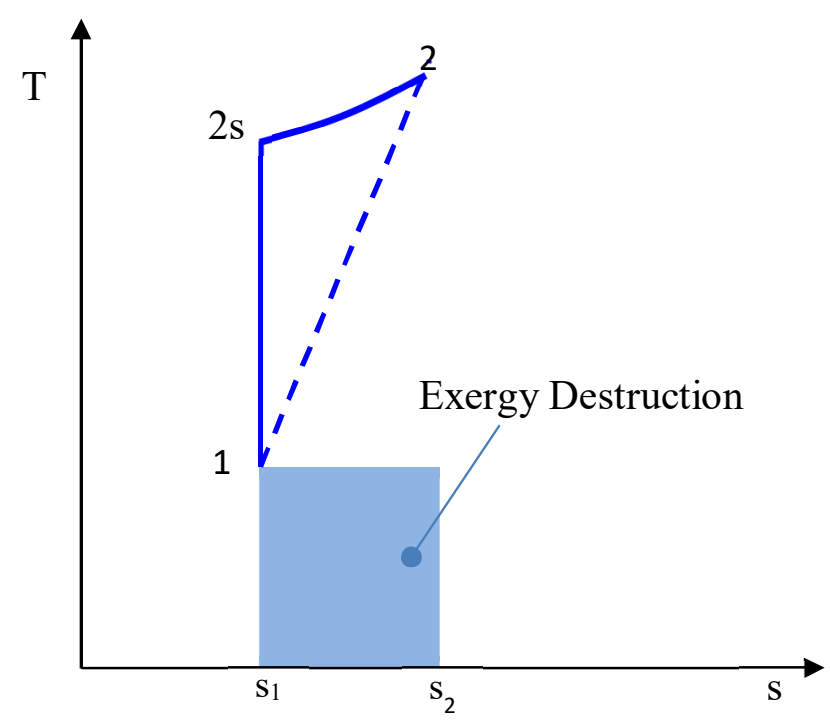

Fig.1. Typical compressor T-s diagram.

\section{SYSTEM ANALYSIS}

The temperature at the compressor exit can be expressed as:

$$
\mathrm{T}_{2}=\mathrm{T}_{1} \pi^{\left(\frac{\mathrm{R}_{\mathrm{m}}}{\mathrm{C}_{\mathrm{pm}} \eta_{\mathrm{p}}}\right)}
$$

Where $\mathrm{C}_{\mathrm{p} m}$ is the specific heat at constant pressure, $\mathrm{R}_{\mathrm{m}}$ is the gas constant of the humid air and the subscript $m$ indicates the moist air. In order to determine $T_{2}$, both $C_{p m}$ and 
$\mathrm{R}_{\mathrm{m}}$ have to be specified. To perform this, the specific humidity at $\mathrm{T}_{1}$ defined as the mass of water vapor in a unit mass of moist air can be written as (Martínez et al. (2011)):

$$
\omega_{1}=\frac{0.622 \times \mathrm{RH}_{1} \times \mathrm{P}_{\text {sat1 }}}{\mathrm{P}_{1}-\mathrm{RH}_{1} \times \mathrm{P}_{\text {sat } 1}}
$$

Where $\mathrm{RH}_{1}$ is relative humidity at $\mathrm{T}_{1}, \mathrm{P}_{1}$ is the pressure at compressor inlet, $\mathrm{P}_{\text {sat }}$ is the inlet pressure at saturation condition, $\mathrm{R}$ is the gas constant. The vapor mass fraction, VMF, is expressed as:

$$
\mathrm{VMF}=\frac{\omega_{1}}{1+\omega_{1}}
$$

Therefore, the air mass fraction, $\mathrm{AMF}$, can be written as:

$$
\mathrm{AMF}=1-\mathrm{VMF}
$$

The gas constant of mixture, $R_{m}$ can be determined by the following equation:

$$
\mathrm{R}_{\mathrm{m}}=\frac{\mathrm{R}}{\mathrm{MMW}}
$$

Where MMW is the mixture molecular weight. The following formula can specify the specific heat of humid air:

$$
\mathrm{C}_{\mathrm{pm}}(\mathrm{T})=\mathrm{C}_{\mathrm{pa}}(\mathrm{T})+\mathrm{w} \times \mathrm{C}_{\mathrm{pv}}(\mathrm{T})
$$

Where the temperature ( $T$ ) may equal to $T_{1}$ or $T_{2}$. Here, $T_{2}$ can be determined by partial pressures and molecular weights of dry air and water vapor. The average specific heat of humid air during the process $1-2$ is considered as:

$$
\mathrm{C}_{\mathrm{pmav}}=\frac{\mathrm{C}_{\mathrm{pm} 1}+\mathrm{C}_{\mathrm{pm} 2}}{2}
$$

The isentropic exponent of the humid air is expressed as:

$$
\mathrm{K}=\frac{\mathrm{C}_{\mathrm{pmav}}}{\mathrm{C}_{\mathrm{pmav}}-\mathrm{R}_{\mathrm{m}}}
$$

Therefore, the exit isentropic temperature is given by the following formula:

$$
\mathrm{T}_{2 \mathrm{~s}}=\mathrm{T}_{1} \times \pi^{\left(\frac{\mathrm{K}-1}{\mathrm{~K}}\right)}
$$

The compressor isentropic efficiency or the compressor first law efficiency is defined as:

$$
\eta_{\mathrm{I}}=\frac{\mathrm{C}_{\mathrm{pm} 2 \mathrm{~s}} \mathrm{~T}_{2 \mathrm{~s}}-\mathrm{C}_{\mathrm{pm} 1} \mathrm{~T}_{1}}{\mathrm{C}_{\mathrm{pm} 2} \mathrm{~T}_{2}-\mathrm{C}_{\mathrm{pm} 1} \mathrm{~T}_{1}}
$$


The actual specific compressor work consumption can be expressed by the following equation:

$$
\mathrm{w}=\mathrm{C}_{\mathrm{pm} 2} \times \mathrm{T}_{2}-\mathrm{C}_{\mathrm{pm} 1} \times \mathrm{T}_{1}
$$

The exergy destruction can be expressed as:

$$
\mathrm{I}_{\mathrm{des}}=\mathrm{T}_{1}\left(\mathrm{~s}_{2}-\mathrm{s}_{1}\right)
$$

Where $s_{1}$ and $s_{2}$ are the specific entropy of the humid air at inlet compressor and outlet, respectively. The exergy destruction ratio can be written as:

$$
\mathrm{I}_{\mathrm{des}} \text { ratio }=\frac{\mathrm{I}_{\mathrm{des}}}{\mathrm{W}}
$$

The exergy destruction evaluates the inefficient use of available energy, while the exergy destruction ratio evaluates this unavailable inefficient use relative to the compressor work. Accordingly, using exergy destruction and exergy destruction ratio gives different insights in understanding the compressor performance. The reversible work is given by the following equation:

$$
\mathrm{w}_{\text {rev }}=\mathrm{w}-\mathrm{I}_{\text {des }}
$$

Where $\mathrm{w}_{\text {rev }}$ is the minimum required work that might be used to compress humid air from state 1 to state 2 . The second law efficiency can be expressed as:

$$
\eta_{\text {II }}=\frac{\mathrm{w}_{\mathrm{rev}}}{\mathrm{w}}
$$

\section{RESULTS AND DISCUSSION}

The compressor parameters investigated in the present paper are; polytropic efficiency, compressor pressure ratio, inlet temperature, and inlet humidity. The effects of these parameters are demonstrated on compressor specific work consumption, exergy destruction, exergy destruction ratio, the first law efficiency, and second law efficiency. The results were performed by EES software version 4.817. For performing simulations, Table 1 summarizes the values of these different parameters unless otherwise are specified.

Table 1. Different studied parameters

\begin{tabular}{ll}
\hline \hline Parameters & Parameter range or values \\
\hline \hline Compressor inlet temperature & $288 \mathrm{~K}, 298 \mathrm{~K}, 308 \mathrm{~K}$, and $318 \mathrm{~K}$ \\
\hline Compressor pressure ratio & $4-20$ \\
\hline Polytropic efficiency & $0.8,0.85$, and 0.9 \\
\hline Inlet relative humidity & $0-100 \%$ \\
\hline
\end{tabular}


The relationship between specific compressor work consumption (specific work) and exergy destruction at $\mathrm{RH}=0.6$ as an example is represented in Fig. 2. The data are presented for different pressure ratios $(\pi=4,8,12,16$ and 20) and different inlet temperatures $\left(T_{1}=288 \mathrm{~K}, 298 \mathrm{~K}, 308 \mathrm{~K}\right.$, and $\left.318 \mathrm{~K}\right)$ at three different polytropic efficiencies. It is observed that the increase in specific work consumption leads to more exergy destruction. Moreover, exergy destruction that is the measure of more irreversibility is increased with the raising of $\pi, T_{1}$, and with the reduction of $\eta_{p}$. The effect of inlet temperature and $\pi$ on exergy destruction is more sensible with the reduction of polytropic efficiency. This figure gives a picture of the values for different values of compressor work, and affected by the inlet temperature, pressure ratio, and polytropic efficiency.

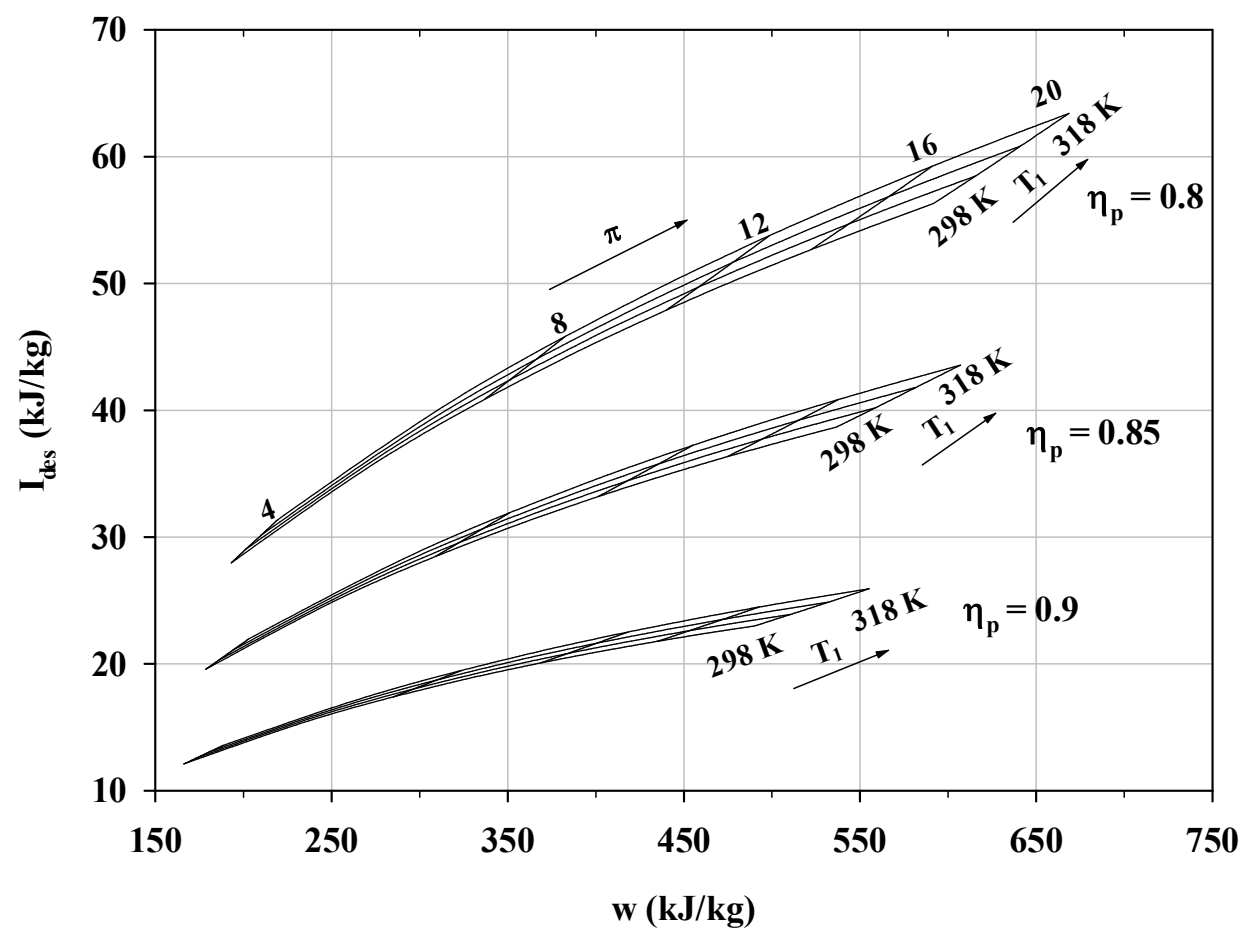

\section{Fig. 2. Exergy destruction versus specific work at $\mathbf{R H}=0.6$ (different examined $\pi$, inlet temperatures, and polytropic efficiencies).}

Fig. 3 demonstrates the exergy destruction ratio versus specific work consumption at $\mathrm{RH}$ $=0.6$. The exergy destruction ratio represents another view of the unavailable work with respect to specific work. On the contrary to the exergy destruction trend, the exergy destruction ratio is inversely proportional to specific work consumption. The increase of compressor pressure ratio and reduction of the ambient inlet temperature result in lowering the exergy destruction ratio. From Fig. 2 and Fig. 3, it can be noticed that different compressor performance can be evaluated by two different criteria. In Fig. 2, 
exergy destruction gives the quantity of available losses. On the other side, the exergy destruction ratio (Fig. 3) gives a deeper picture in which the available losses are relative to compressor work. Exergy destruction and exergy destruction ratio have different trends owing to the latter is inversely proportional to compressor work consumption. Accordingly, choosing the compressor with less exergy destruction or exergy losses may a deceptive scale in evaluating the compressor. Here, the exergy destruction ratio gives better evaluation or selection for different compressors.

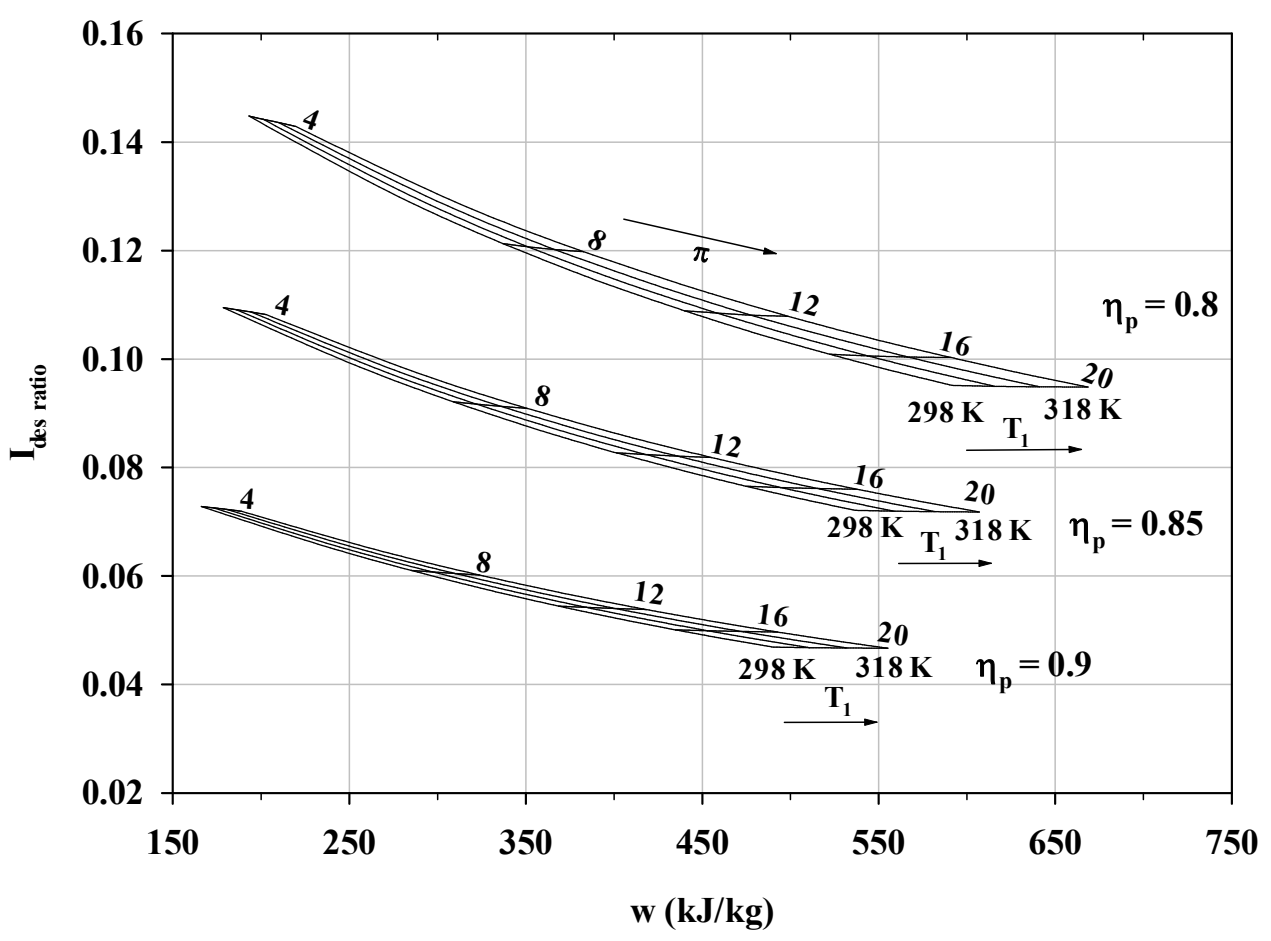

Fig. 3. Exergy destruction ratio versus specific work at $\mathbf{R H}=0.6$ (different examined $\pi$, inlet temperatures, and polytropic efficiencies).

Figs. 4, 5 and 6 depict the relation between first and second law efficiencies versus specific work at polytropic efficiency equals $0.8,0.85$ and 0.9 , respectively. Such relation is demonstrated at $\mathrm{RH}$ equals 0.6 for the three figures. It is observed from the plotted data that increasing of compressor pressure ratio leads to reduction of first law efficiency and raising of compressor work consumption and second law efficiency. Furthermore, the reduction of the polytropic efficiency results in a decrease in first law efficiency, second law efficiency, specific work consumption, and specific work operation domain. The inlet temperature has insensible effects on first and second law efficiencies, while it has a great positive effect on specific work. The effect of inlet 
temperature and pressure ratio parameters is reduced with the increase of polytropic efficiency.

First and second law efficiencies show different trends is owing to the latter depends on the exergy destruction. This gives two different points of view to understand deeply compressor performance. It is notable that first law efficiency may be a deceptive scale in evaluating the compressor since it focusses on the energy quantity. On the other side, second law efficiency provides quantitative compressor performance assessment. The result charts help in evaluating or selecting different types of compressors that having higher second law efficiency or having less exergy destruction ratio.

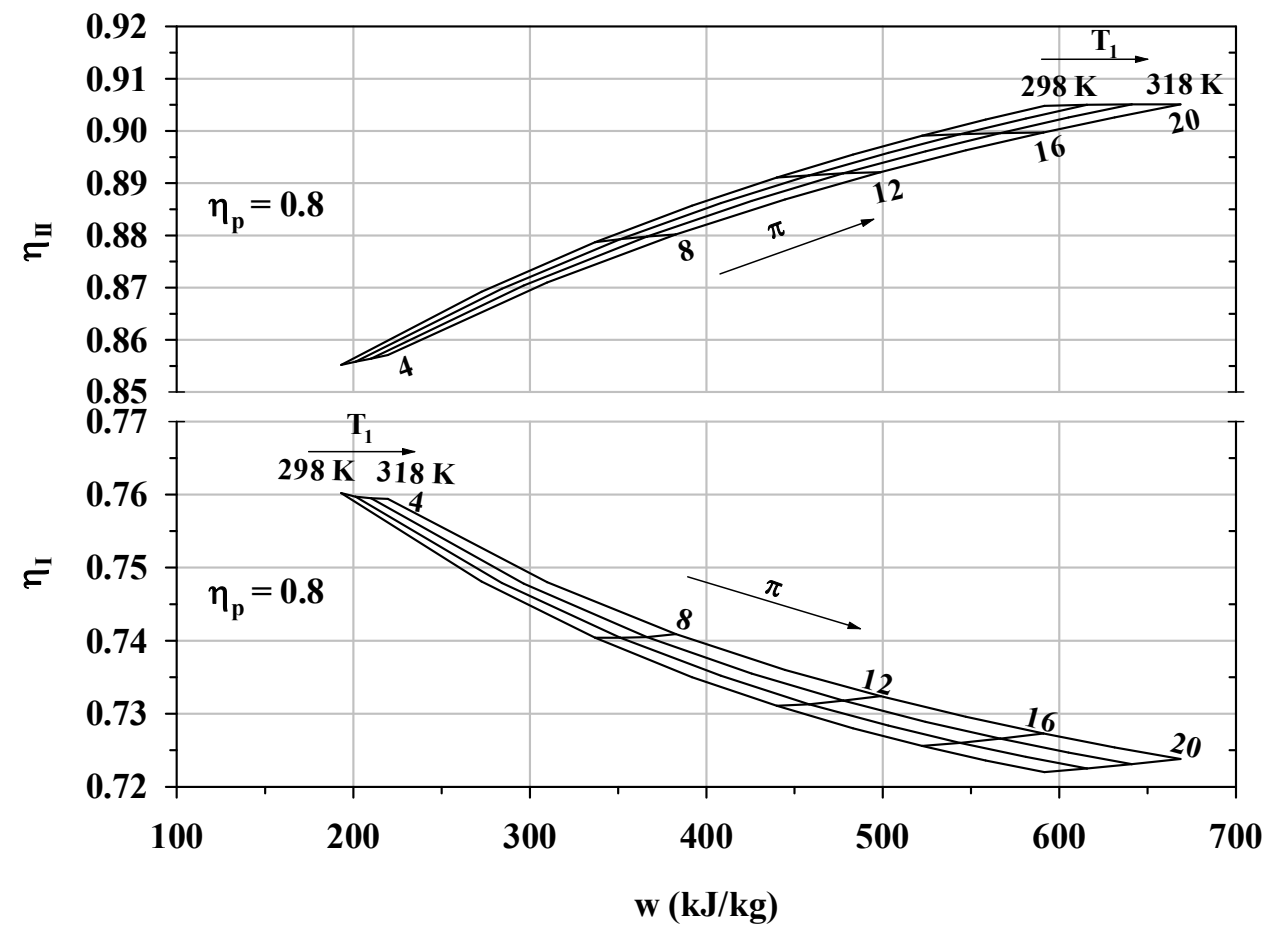

Fig. 4. First and second law efficiencies versus specific work at $R H=0.6$ and $\eta_{p}=$ 0.8 (different examined $\pi$ and inlet temperatures). 


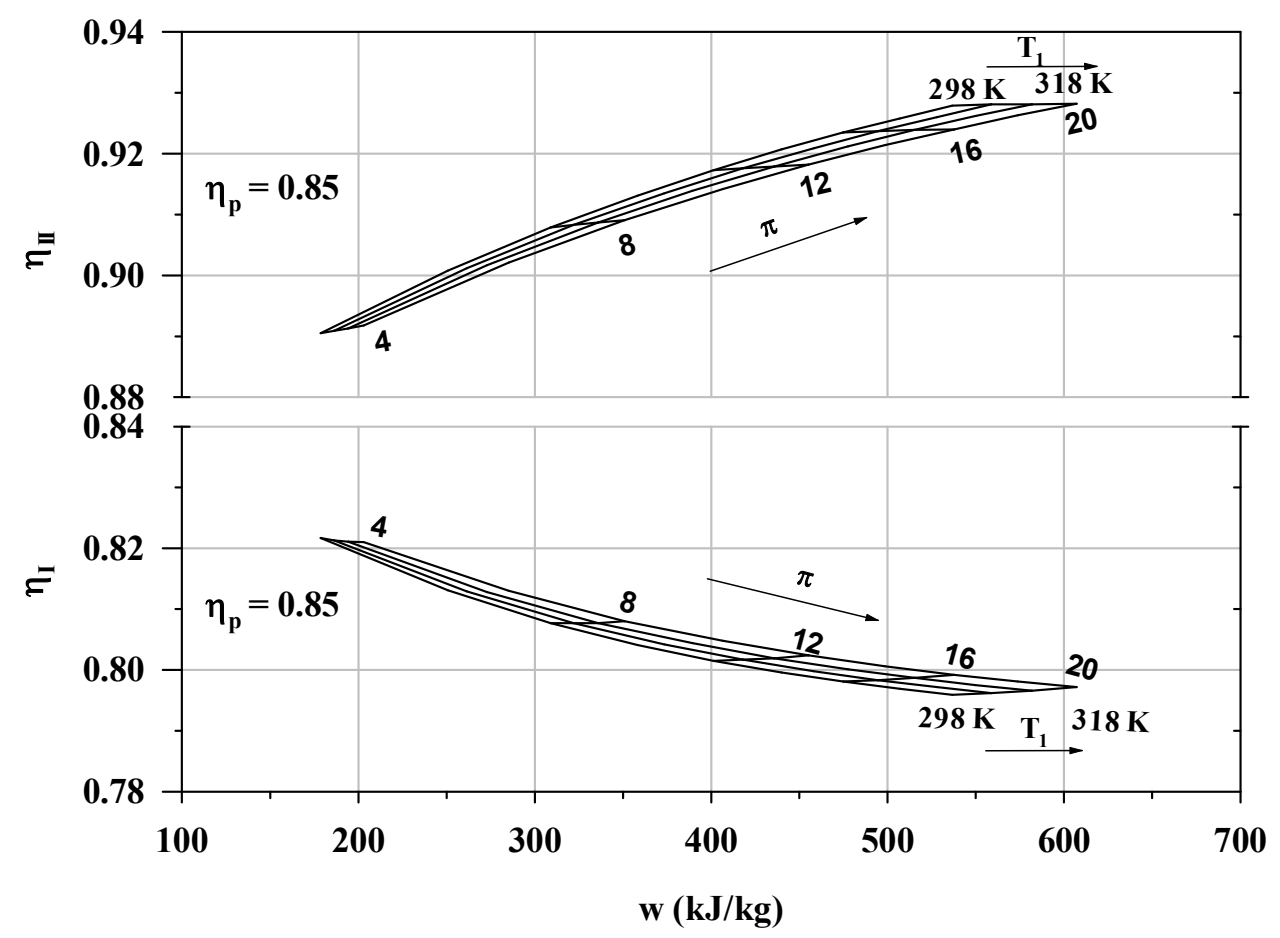

Fig. 5. First and second law efficiencies versus specific work at $\mathrm{RH}=0.6$ and $\eta_{\mathrm{p}}=$ 0.85 (different examined $\pi$ and inlet temperatures).

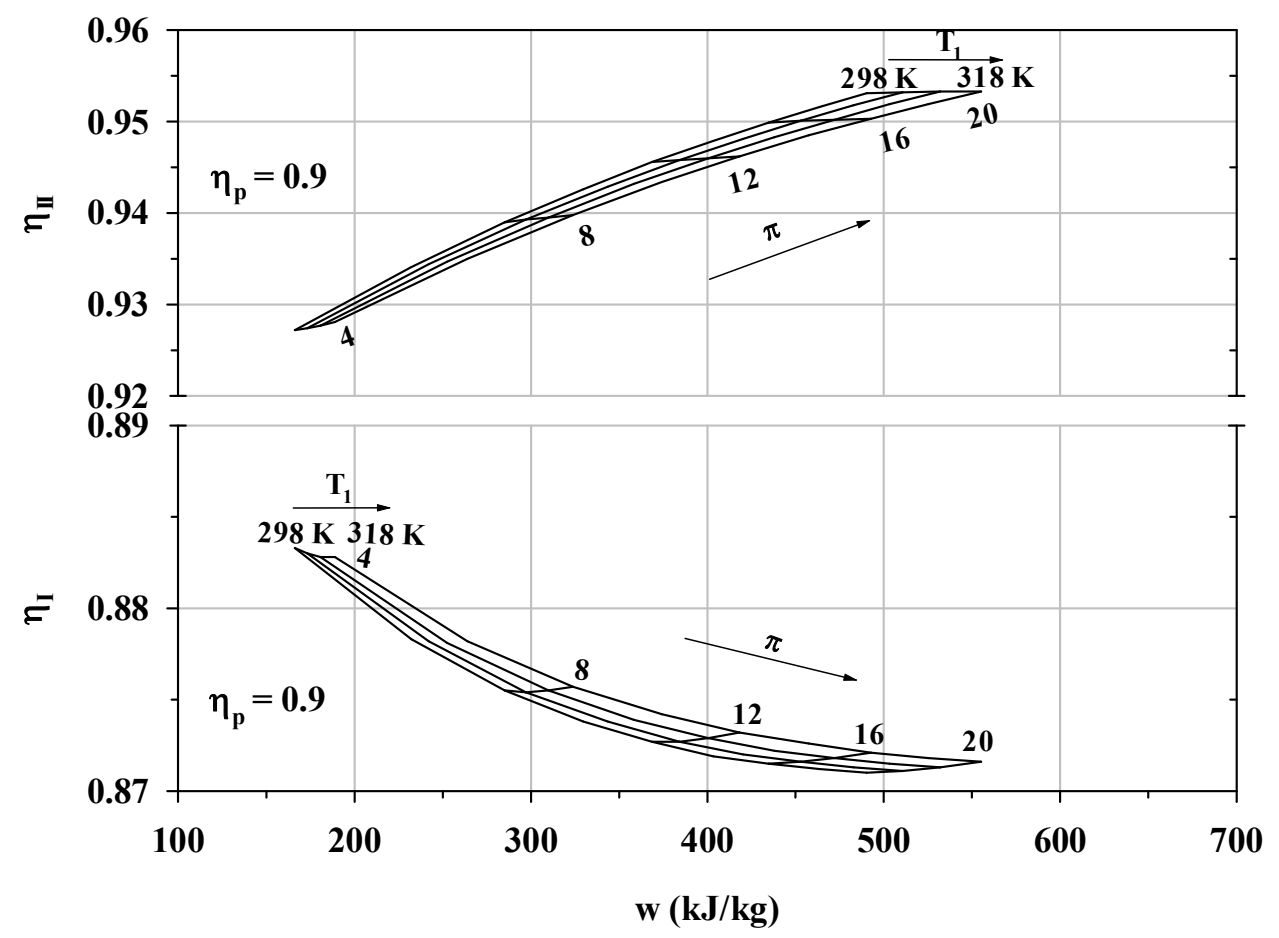

Fig. 6. First and second law efficiencies versus specific work at $\mathrm{RH}=0.6$ and $\eta_{\mathrm{p}}=$ 0.9 (different examined $\pi$ and inlet temperatures). 
Fig. 7 shows the effect of RH on specific work consumption at the minimum and maximum examined pressure ratio and ambient temperature $\left(\pi=4\right.$ and 20 and $\mathrm{T}_{1}=288$ $\mathrm{K}$ and $318 \mathrm{~K}$ ). This gives a global picture of the effect of $\mathrm{RH}$ on specific work at the boundaries of the examined ratio of pressure ratio and inlet temperatures. In general, specific work shows a sensible variation with $\mathrm{RH}$. The effect of RH on specific work appears more sensibly at $\mathrm{T}=318 \mathrm{~K}$ than at $\mathrm{T}=288 \mathrm{~K}$. Increase of $\mathrm{RH}$ leads to varying the thermodynamic properties of the air and thus leads to increase in the specific work.

Fig. 8 illustrates the relationship of specific work consumption and its percentage with $\mathrm{RH}$ for pressure ratio equals 16 at different inlet temperatures. The reference base of percentage specific work increase is taken at a hypothetical value, at zero RH. Negligible effect of the RH is noticed on the specific work at low temperatures, whereas, it increases as the inlet temperature increases. The increment percentage of the specific work is depicted and illustrated on the same figure.

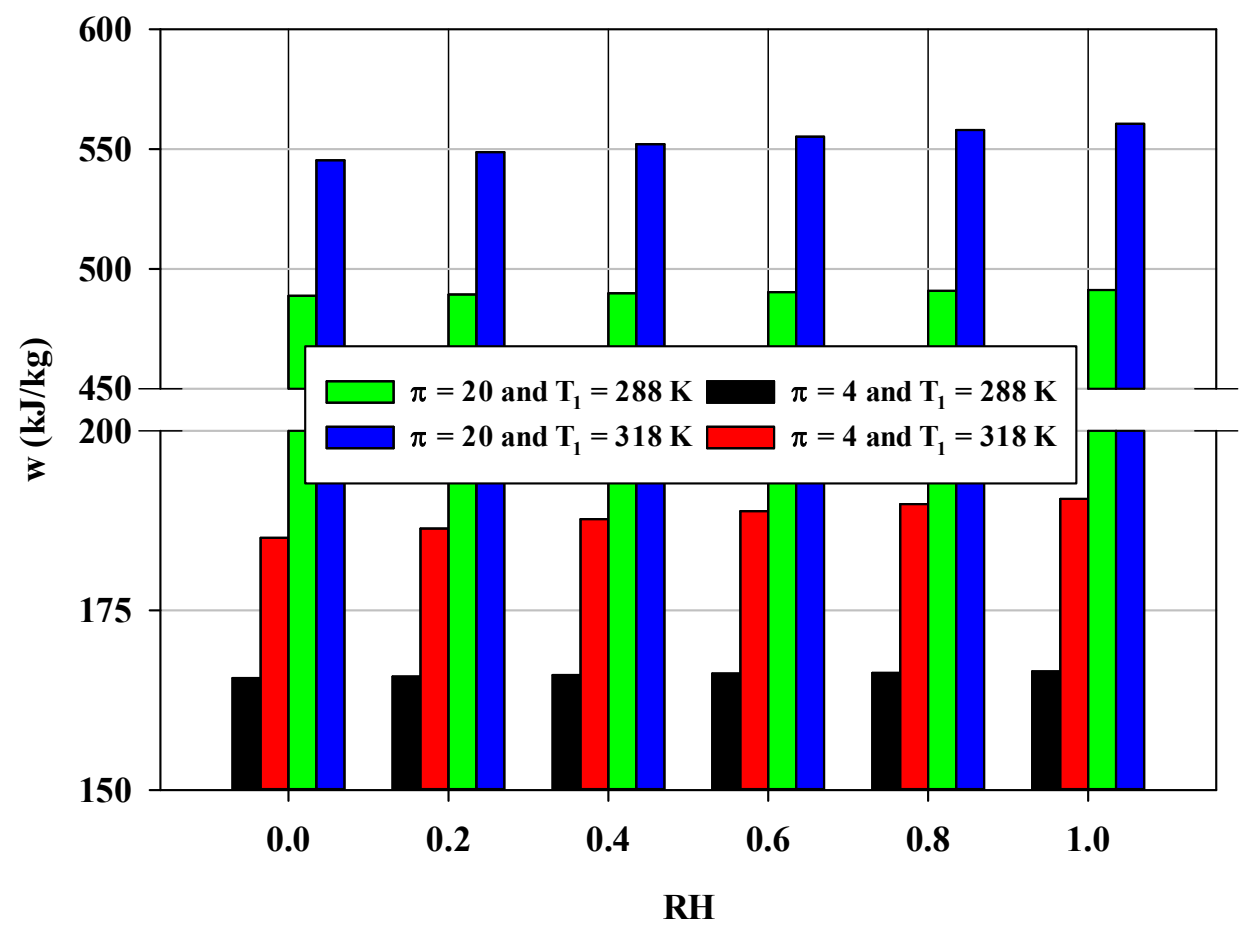

Fig. 7. Specific work versus $R H\left(\eta_{p}=0.9, \pi=4\right.$ and 20 , and $T_{I}=288 K$ and $\left.318 K\right)$. 


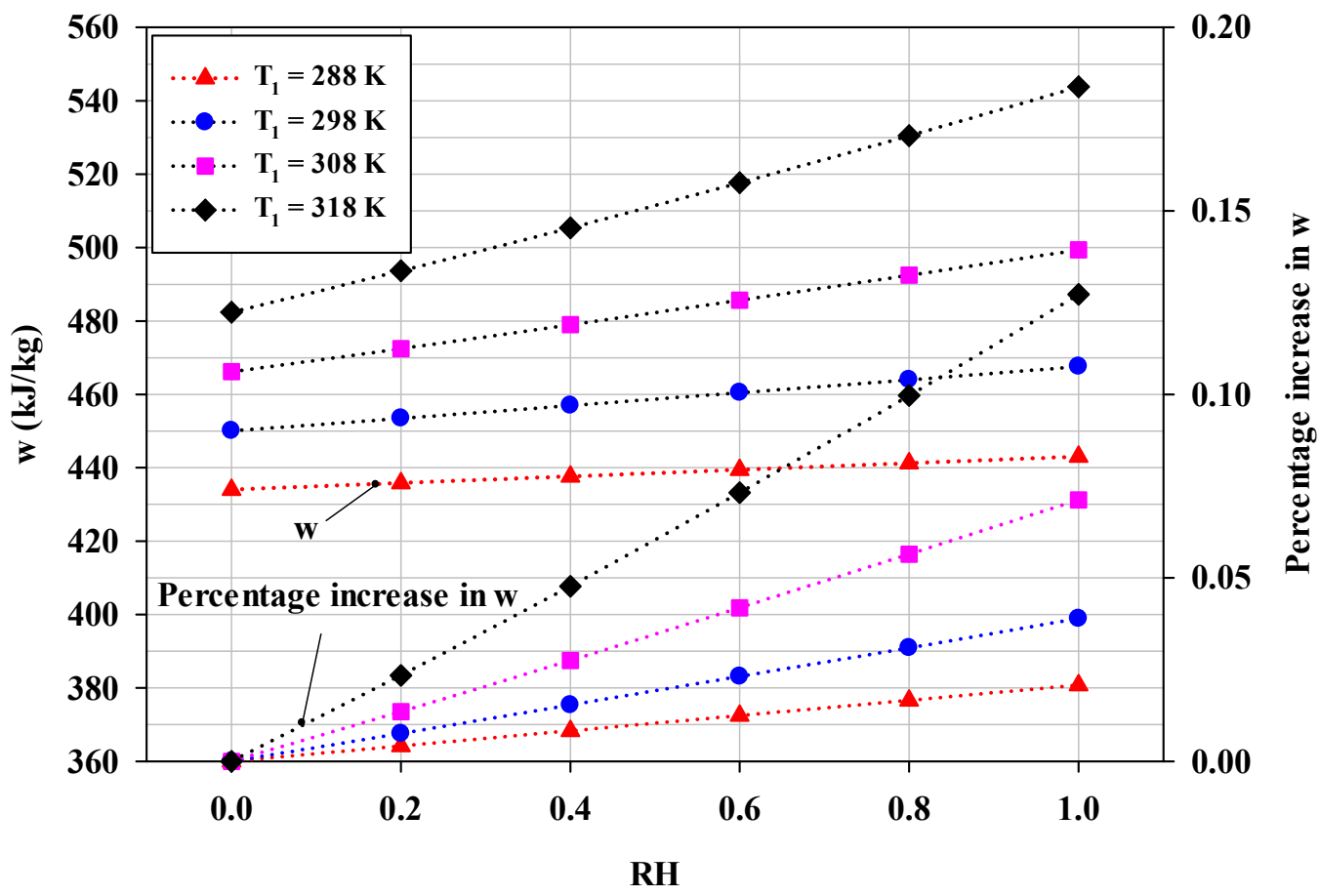

Fig. 8. Specific work and its percentage increase versus RH ( $\pi=16$ and different examined inlet temperatures).

Figs. 9 and 10 demonstrate the effect of RH on the first and second law efficiencies, respectively. The results are depicted for the minimum and maximum examined temperatures $(288 \mathrm{~K}$ and $318 \mathrm{~K}$ ) and minimum and maximum examined pressure ratios ( $\pi=4$ and 16). In general, it is observed that RH has a diminutive effect on first and second law efficiencies throughout its different values from 0 to 1 . In the case of inlet temperature equals $318 \mathrm{~K}$ and $\pi=4$ and 16 , first law efficiency shows a slight effect with the increase of RH. The insignificant variation of the first law efficiency may be due to the change of actual and isentropic work is nearly the same in the case of fist law efficiency. Also, in case the second law efficiency, this may be due to the change of the actual work, and reversible work is nearly the same. 


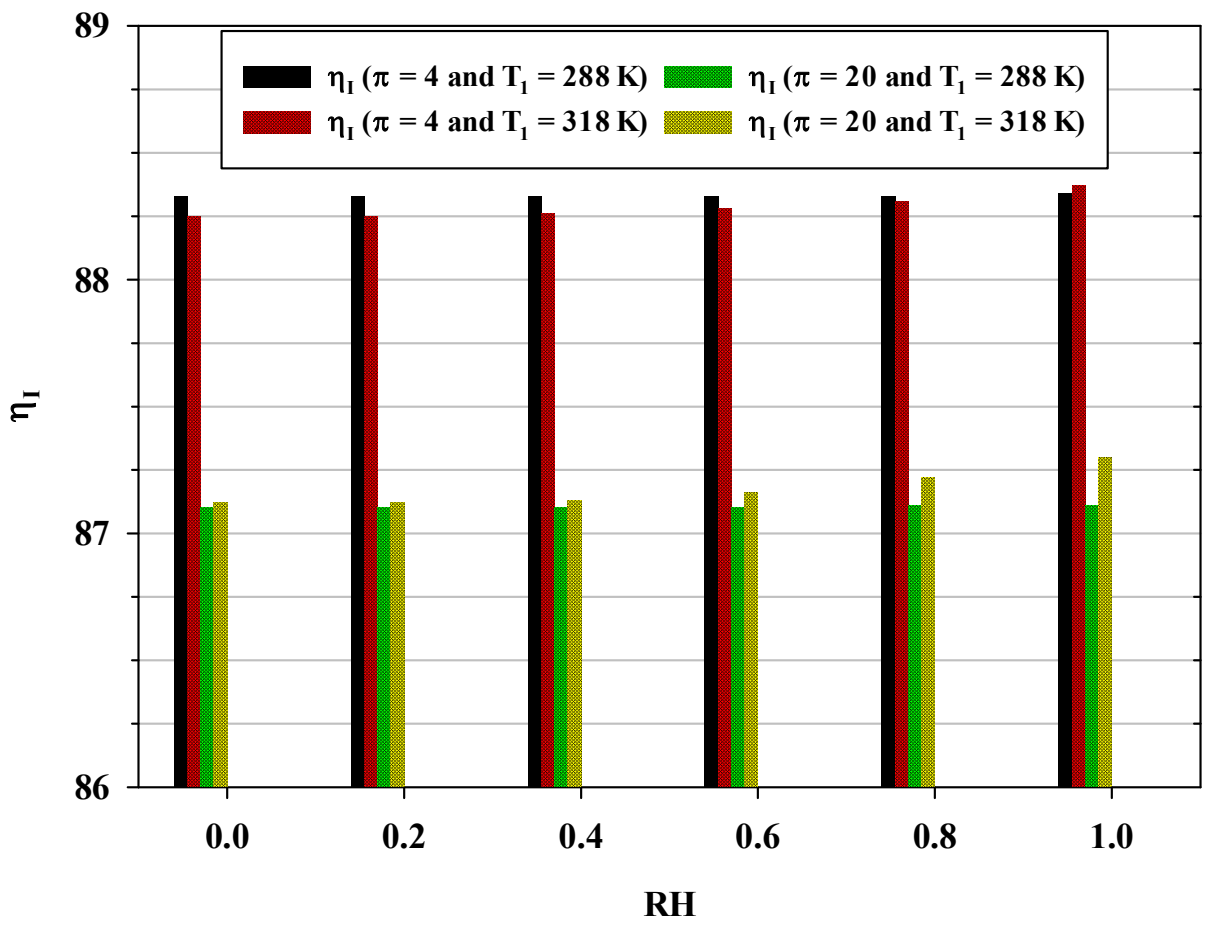

Fig. 9. First law efficiency versus RH $\left(\eta_{\mathrm{p}}=0.9, \pi=4\right.$ and 20 , and $\mathrm{T}_{\mathrm{I}}=288 \mathrm{~K}$ and $\left.318 \mathrm{~K}\right)$.

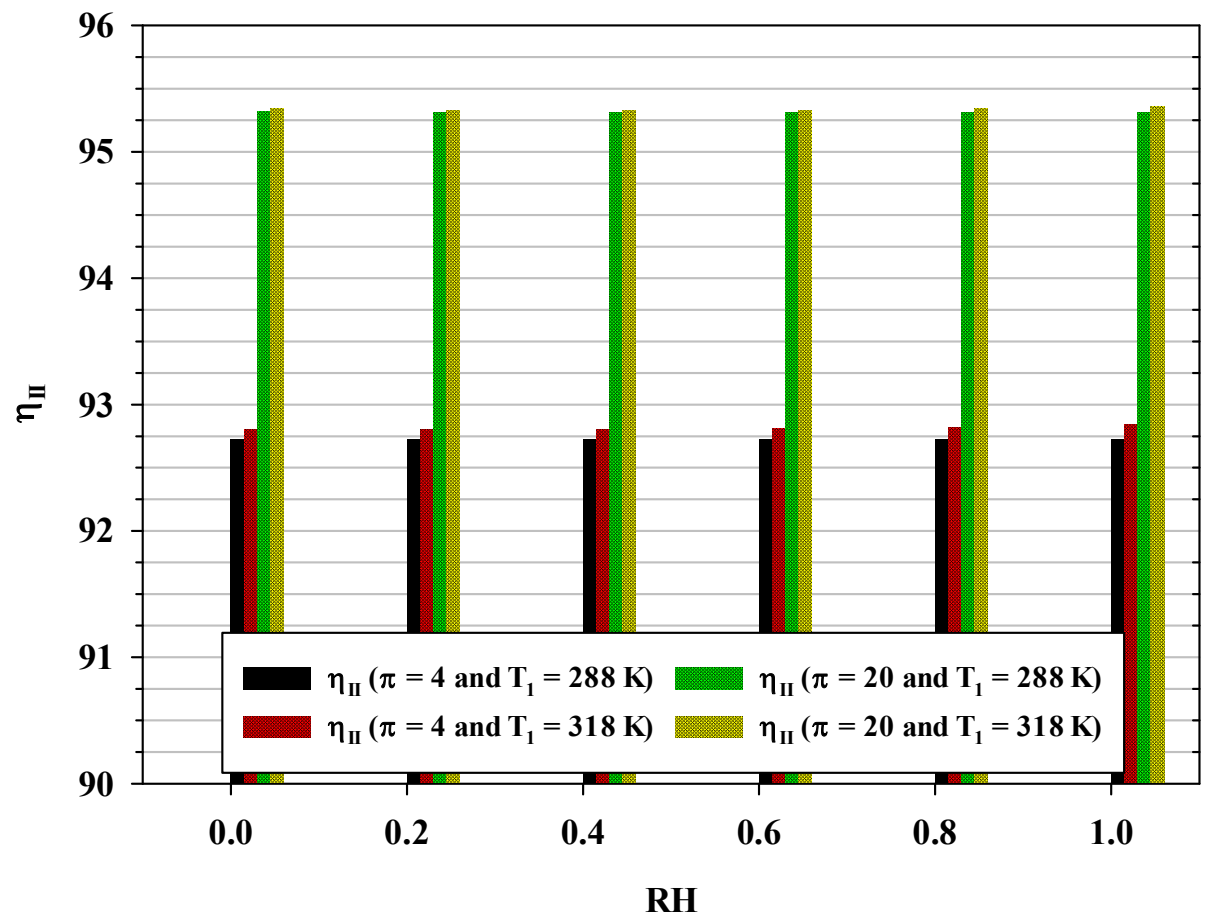

Fig. 10. Second law efficiency versus RH $\left(\eta_{\mathrm{p}}=0.9, \pi=4\right.$ and 20 , and $T_{I}=288 \mathrm{~K}$ and $\left.318 \mathrm{~K}\right)$. 


\section{CONCLUSIONS}

The present work utilizes energy analysis and exergy analysis to demonstrate compressor performance with different aspects and insights. The following conclusions can be drawn according to the examined values of parameters:

1. First and second law efficiencies provide quantitative and qualitative compressor performance assessments, respectively. The present charts help in evaluating or selecting different types of compressors that having higher second law efficiency or having less exergy destruction ratio.

2. Increasing the compressor work consumption results in more exergy destruction and less exergy destruction ratio.

3. Increasing of polytropic efficiency has a significant effect on specific work reduction, reducing destructive exergy and increase first and second law efficiencies.

4. Reduction of specific work consumption and second law enhancement are noticeably affected by reducing the inlet air temperature. First and second law efficiencies are merely affected by the inlet temperature variations.

5. Increase of compressor pressure ratio results in increasing of specific work consumption and the second law efficiency. On the other side, first law efficiency is reduced.

6. First and second law efficiencies are insignificantly affected by ambient relative humidity. However, specific work is increased with the increase of relative humidity.

\section{REFERENCES}

Abd El-Maksoud R.M., Bayomi N.N., and Rezk M.I.F., "Centrifugal compressor map prediction and modification", Journal of King Abd El Aziz University, Engineering Science, 2013.

Bader W.T., and Kissock J.K., "Exergy Analysis of Industrial Air Compression", Proceedings from the Twenty-second National Industrial Energy Technology Conference, Houston, TX, April 5-6, 2000.

Bayomi N.N., and Abd El-Maksoud R.M., "Two operating modes for turbocharger system", Energy Conversion and Management, vol. 58, pp. 59-65, 2012.

Betelmal E.H., and Farhat S. A.," Energy and Exergy Analysis of a Simple Gas Turbine Cycle with Wet Compression”, Mechanical Engineering Research; vol. 8, no. 1, 2018.

Martínez F.R., Martínez A.A.R., Velázquez, M.T., Diez P.Q., Eslava G.T., and Francis J. A., "Evaluation of the gas turbine inlet temperature with relation to the excess air", Energy and Power Engineering, vol. 3, pp. 517-524, 2011. 
Mascarenhas J.D.S., Chowdhury H., Thirugnanasambandam M., Chowdhury T., and Saidur R., "Energy, exergy, sustainability, and emission analysis of industrial air compressors", Journal of Cleaner Production, vol. 231 pp.,183-195, 2019.

Mohamed M.I., Abd El-Maksoud R.M., Noussier Z.B., and Amer F.Z., "Surge avoidance using speed and valve methodologies controlled by PID, fuzzy and neural networks approaches", The 2011 International Conference on Computer Engineering and Systems (ICCES'2011), IEEE, 2011.

Mohtaram S., Chen W., Zargar T., and Lin J., "Energy-exergy analysis of compressor pressure ratio effects on thermodynamic performance of ammonia water combined cycle”, Energy Conversion and Management, vol. 134, pp. 77-87, 2017.

Mousavi S., Kara S., and Kornfeld B., "Energy efficiency of compressed air systems", Procedia CIRP, vol. 15, pp. 313-318, 2014.

Niazmand A., Farzaneh-Gord M., and Deymi-Dashtebayaz M., "Exergy analysis and entropy generation of a reciprocating compressor applied in CNG stations carried out on the basis models of ideal and real gas", Applied Thermal Engineering, vol. 124, pp. 1279-1291, 2017.

Ogbonnaya M., Ajayil O.O., Waheed M.A and Oyedepo S.O., "Review on the energy and exergy analysis of vapour compression refrigeration system using nanolubricant", Journal of Physics: Conference Series, vol. 1378, 2019.

Oldrich J., "Isentropic efficiency of centrifugal compressor working with real gas", Acta Polytechnica CTU Proceedings, vol. 20, pp. 65-72, 2018.

Shukla A.K., and Singh O., "Effect of compressor inlet temperature \& relative humidity on gas turbine cycle performance", International Journal of Scientific \& Engineering Research, vol. 5, Issue 5, 2014.

Szablowski L., Krawczyk P., Badyda K., Karellas S., Kakaras E., and Bujalski W., "Energy and exergy analysis of adiabatic compressed air energy storage system" Energy, vol. 138, vol. 1, pp. 12-18, 2017.

$\mathrm{Xu}$ C., and Amano R.S., "Study of the flow in centrifugal compressor", International Journal of Fluid Machinery and Systems, vol. 3, no. 3, 2010.

Yang B., Fang X., Zhang L., Zhuang F., and Wang X., "Applicability of empirical models of isentropic efficiency and mass flow rate of dynamic compressors to jet engines”, Progress in Aerospace Sciences, vol. 106, pp. 32-42, 2019. 